\title{
How to Influence Total Costs of Sourcing? A Case Study of SCOPQ With Six Sigma
}

\author{
Rubén Medina Serrano ${ }^{1 *}, \mathrm{M}^{\mathrm{a}}$ Reyes González Ramírez ${ }^{1}$, José Luis Gascó ${ }^{1}$, and Wanja Wellbrock ${ }^{2}$ \\ ${ }^{1}$ University of Alicante, Spain \\ ${ }^{2}$ University of Heilbronn, Germany
}

\section{ARTICLE INFO}

\section{Keywords:}

$C O P Q$

DMAIC

Supplier quality

Supplier performance

Lean Six Sigma (LSS)

\begin{abstract}
Total cost of sourcing is receiving significant attention from firms in general and purchasing managers in particular. Academic research on lean and six sigma programs has evolved rapidly in the last decade. This study focuses on uncovering most effective sourcing initiatives, which aim to decrease total costs addressing quality issues and Supplier Costs of Poor Quality (SCOPQ). This research aims to update the literature on supply chain management by analysing and verifying the proposed Six Sigma framework through a case study. A case study focused on a set of interviews with practitioners based on a firm located in Germany was used that generates uncaptured insights in previous research of this area. The results of the paper highlight the relevance of building cross-functional teams for achieving continuous improvement and implementing suitable, proven, and appropriated tools. Whereas lean is preferred for scopes as part of processes with few interfaces and medium grade of difficulty, Six Sigma is the most suitable methodology for scopes with a high grade of difficulty or problems involving cross-functional processes. SCOPQ is defined as the costs associated with defects and deficiencies originated by suppliers. For instance, they could include the costs for supplier-related incidents like shortages or failure-related costs, production stop costs, rework costs, complaints, etc. This research not only validates the proposed framework through an in-firm case study, but also confirms the relevance of mitigating and avoiding biases, recommends standardizing processes and texts templates, and the regularly training of the employees involved. Besides of the main goal of investigating Six Sigma's role in reducing quality costs, research results demonstrate the advantage of standardized multilingual texts for the complaint process of global players. The study indentified the influence of English collocations into the complaint process because of the majority of the specialized literature is written in English.
\end{abstract}

\section{Introduction}

What is Cost of Quality (COQ)? COQ summarizes the total of conformance and nonconformance (COPQ) costs.According to Snee (1999) and Murumkar et al. (2018), the Six Sigma methodology allows firms to save costs by identifying and eliminating failure causes

\footnotetext{
* Corresponding author E-mail address: ruben.medina.serrano@googlemail.com

Cite this article as:

Medina Serrano, R., González-Ramírez, R., Gascó, J. L., \& Wellbrock, W. (2021). How to Influence Total Costs of Sourcing? A Case Study of SCOPQ With Six Sigma. International Journal of Applied Research in Management and Economics, 4(1), 30-49. https://doi.org/10.33422/ijarme.v4i1.480
}

(C) The Author(s). 2021 Open Access. This article is distributed under the terms of the Creative Commons Attribution 4.0 International License, which permits unrestricted use, distribution, and redistribution in any medium, provided that the original author(s) and source are credited. 
in processes. In fact, firms can employ this methodology to get benefits and achieve stable and standardized processes, with a reduction in systematic failures, process variations and defects. Whereas COPQ is mainly affected by service and product failures, cost of conformance is understood as the preventive costs needed to avoid poor quality. Costs of conformance are for instance audit costs, monitoring costs and incoming quality inspection costs (Murumkar, Teli and Loni, 2018; Machowski, and Dale, 1998). COPQ has drawn much attention from the research community in the last decade, with firms and universities focused on the need to save costs. In a B2B environment, a complaint is a recurring element of the daily work for vendors and customers. Thus, there exists the need to systematically collect and record complaints whenever a firm aims to be ISO 9001 certified. The speed and precision of a complaint answer will highly depend on the quality of the sent failure description. Whereas Shivam, Sachin and Angappa (2020) analyzed 52 articles investigating the application of big data analytics (BDA) to have more confident and predictable decisions in each phase of Lean Six Sigma (LSS), Zahar et al. (2015) conducted a research to determine different quality costs in water analysis laboratories. However, studies on the application of methodologies to improve processes and to save costs at firm's levels are still scarce. Despite the interest in Six Sigma, one of the main gaps in current research is that studies have so far failed to consider the relevance of having trained yellow, green, black belt and master black belts in firms to positively influence the relationship between LSS practices and performance. Although research on phraseology has evolved in the last decades, further studies are warranted to compile and analyze collocations in the LSS and complaint management field. This research work aims to address this gap by producing a complementary entry of phraseological units in English and German used in complaint management. This paper is structured as follows: after the introduction, the next section presents the Six Sigma approach with a literature review. Section 3 describes the research design for the case study and explains the operationalization of the DMAIC methodology as part of the creation of a supplier complaint process and its verification through a case study. Finally, main conclusions and limitations are identified and discussed in Section 4.

\section{Literature Review and Six Sigma Approach}

"Whereas Lean focuses on reducing systematic waste (non-value-added processes and procedures) and promotes work standardization and flow, Six Sigma aims to reduce the variation of the processes, its adverse effects and enhances process control" (ISO 18404, 2015). According to the American Society for Quality (ASQ), LSS is a fact- and data-driven, hybrid methodology of improvement that pursues defect prevention over defect detection (ASQ, 2019). In fact, LSS identifies customer desires, eliminates wastes and reduces variability. Given the growing relevance of the Six Sigma methodology in the last decade, this study has adapted the Six Sigma framework. Besides the five DMAIC (Define, Measure, Analyse, Improve, Control) phases, this research illustrates the relevance of Black Belts, who are experts tasked with implementing LSS methodologies, leading the effectiveness of Six Sigma projects. Six Sigma was introduced by Motorola at its Research Centre in 1987 with a quality goal of 3.4 DPMO, where a defect opportunity is a process failure critical to the customer. This method is intended to achieve continuous significant improvement by eliminating variations in processes. A 3.4 DPMO represents a Sigma level of 6 which means $99.997 \%$ of quality level. At 6,210 DPMO, the Sigma level is 4 with a $99.4 \%$ quality level (Murumkar, Teli and Loni, 2018). The main outputs within the DMAIC phases are: (1) Define (creating a team and appointing a champion; identifying the process; defining opportunities for improvement); (2) Measure (collecting proformas and evidences; data on supplier complaints; supplier delivery performance; supplier-related costs; auditing costs; hidden costs; current variables and KPIs); (3) Analyse (analysing key variables and data); (4) 
Improve (implementing solutions; deploying and implementing the project; getting feedback); (5) Control (creating a training plan; planning for stability); and (6) Measure (measuring benefits). These phases are described in detail in the case study in Section 3.1. Researchers like Gaikwad et al. (2016) applied the DMAIC framework in different contexts. Many expressions employed in complaint management were compiled from a specialized dictionary, namely Herbst and Amman's (2000) Dictionary of Commercial and Legal Terms. For example, "cause for complaint" is translated as Grund $(m)$ zur Beschwerde in German and as sujet $(\mathrm{m})$ de plainte in French. Subject of complaint is translated as Beschwerdegrund $(m)$ and sujet $(m)$ de plainte in German and French respectively. Interestingly, the genre of both translations in French and German are in masculine. Another examples are (1) statement of claim translated as Klageschrift $(f)$ and acte $(m)$ introductif d'instance and (2) bill of complaint translated as Beschwerdeschrift $(f)$ and acte $(m)$ de pourvoi. From their dictionary viewpoint, this research contributes to the literature in this field by performing a practical contrastive analysis. To the complain- A verb from the Table 1, can be formulated further expressions, namely: express grief; Beschwerde führen; formuler un plainte; to complain to $\mathrm{sb}$; sich bei jdm. Beschweren; adresser une réclamation à q; réclamer auprès de q. Additional nouns related to the complaint process itself are identified like A nouncomplainant, complainer; Kläger(in) $m(f)$; demandeur $(m)$; demanderesse $(f)$; plaignant $(e)$ $m(f)$. B noun-complainer; Beschwerdeführer(in) $m(f)$;réclameur $(m)$; réclameuse $(f)$. C nouncomplainer; Nörgler $(m)$;

mécontent $(\mathrm{m})$; grondeur $(\mathrm{m})$. The formation of the feminine noun in the examples above differs between German and French. Whereas the suffix-in is used like Kläger to Klägerin, the French variation is compound by adding the suffix -esse like demanderesse. The morphemes construction added at the end of a word to form a derivative genre differs from German to French. A summary of some of the analyzed expressions found in the abovementioned dictionary is provided in Table 1 .

Table 1.

List of analyzed expressions related to auditing

\begin{tabular}{|c|c|c|c|c|}
\hline Terminology & Grammar & & Expressions & \\
\hline & & English & German & French \\
\hline Complain & A verb & to complain against sth. & sich gegen etw. beschweren & $\begin{array}{c}\text { réclamer (porter } \\
\text { plainte) contre qch. }\end{array}$ \\
\hline Complain & $B$ verb & to complain to sb. & sich bei jdm. beklagen & se plaindre à q. \\
\hline Complain & $\mathrm{C}$ verb & to complain about sth. & etw. bemängeln & trouver à redire à qch. \\
\hline Complaint & A noun & cause for complaint & $\begin{array}{c}\text { Grund }(\mathrm{m}) \text { zur Beschwerde } \\
\text { (zur Klage); } \\
\text { Beschwerdegrund }\end{array}$ & $\begin{array}{c}\text { sujet }(\mathrm{m})(\operatorname{motif}(\mathrm{m})) \\
\text { de plainte }\end{array}$ \\
\hline Complaint & B noun & subject of complaint & Beschwerdegrund (m) & sujet $(\mathrm{m})$ de plainte \\
\hline Complaint & C noun & statement of claim & Klageschrift (f) & $\begin{array}{l}\text { acte }(\mathrm{m}) \text { introductif } \\
\text { d'instance }\end{array}$ \\
\hline Complaint & D noun & bill of complaint & Beschwerdeschrift (f) & acte $(\mathrm{m})$ de pourvoi \\
\hline
\end{tabular}

Mellado Blanco has conducted research into contrastive analysis (2015; 2019); however, while her studies are quite relevant, they do not take into account phraseological units employed in complaint managemnet field. Whereas Gerger and Firuzan, (2016) used the Six Sigma methodology as a process improvement technique in a case study from Turkey, Mahender Singh and Rajeev (2020) developed a Green Lean Six Sigma framework based on the DMAIC approach. Murumkar et al. (2018) developed a framework for reducing quality cost, highlighting that the goal of Six Sigma is the reduction of defects, namely COPQ and, especially, the impact of supplier quality related costs. The present research agrees that it is 
extremely important to track and evaluate the COPQ attributed to firms' suppliers. Laureani and Anton (2017) conducted a literature review about the Leadership and Lean Six Sigma methodologies. Gaikwad et al. (2016) presented an application of Six Sigma in India, and Conger (2015) implemented the Six Sigma methodology for improving an inefficient help desk process. Whereas Vaishnavi and Suresh (2020) analyzed the implementation of Lean Six Sigma in healthcare organizations, Belhadi et al. (2020) analyzed the integrated effect of Big Data Analytics, Lean Six Sigma and Green Manufacturing on the environmental performance of manufacturing firms in North Africa. In 2021 Message Costa et al. (2021) investigated about the application of LSS in the food industry. It can be concluded that the relevance of implementing the Six Sigma methodology to convert inefficient and ineffective processes into efficient and effective ones is observed in the literature. Contrastive studies in the area of "supplier complaint process" for the German-English language pair are still scarce. This paper attempts to address this gap by carrying out an English-German contrastive analysis based on the lexicon-grammar theory (Gross, 1975) and the object class theory (Gross, 1995), focusing on a single class, complaint management (NomComplaint). This paper examines collocations, as defined by Bustos (2020). The collocations analyzed in this research have been mainly extracted from the case study, which provides the corpus of study. The aim is to include the research results in a collocation database that can become a useful tool for the academic community and standardize English-German translations in the complaint management field. In order to solve this need, this research work follows the contrastive analysis methodology employed by Medina Serrano (2020). This research work aims to validate the DMAIC approach improving the supplier complaint activities, developing a standardized supplier complaint process. Within the DMAIC approach, this research work verifies and validates the proposed process through a case study, taking into account the standardization principles of the LSS methodology, standardizing also the reporting and documentation process. In order to effectively standardize the reporting, process a set of standardized texts are created and the related collocations are analyzed and recorded.

\section{Review of The Theoretical DMAIC Framework Through a Case Study of a German Industrial Firm}

In order to develop, adapt and validate the framework, a set of qualitative interviews was undertaken as part of an in-firm case study. Practitioners (product managers, strategic purchasers, production managers, developers and quality managers) were interviewed at a firm located in Germany. Qualitative research was a better fit for the type of questions required for the study. The interviews highlighted the essential importance of practitioners when improving processes at firms. The interviews, the design of the interviews, the analysis of the transcripts and the incorporation of the findings into the study are described here. An analysis of the recent Six Sigma literature was performed and served as the basis for preparing and designing the interviews. From the beginning of the data collection phase, the authors started to decide which information was relevant. Qualitative data analysis was conducted following Miles and Hubermans (1994) methodology, consisting of the following: (1) Data reduction. In this phase, the mass of qualitative data obtained through interview transcripts, observations and notes was reduced and organized, and non-relevant data was discarded. Data was collected through a set of interviews at the firm, and by analysing existing documents and the literature available. (2) Data display. The analysis of mass data was displayed in the form of tables, charts and other graphical formats as an ongoing process by means of the Six Sigma methodological tools. (3) Conclusion. The analysis review was the basis to draw general conclusions, verify and validate the study. Finally, the plausibility and validity of the reviewed data were tested. 
The case study focuses on a leading manufacturer of electronic products. The firm is a global player based in Germany with 1,669 employees and a $€ 275 \mathrm{~m}$ turnover (key figures from the end of 2019). The firm was chosen mainly because of its need to reduce costs of poor quality, especially the costs caused by the high amount of supplier complaints. Besides, one of the authors has a professional relationship with the firm involved, he is Six Sigma Master Back Belt (MBB) certified by the American Society for Quality (ASQ). In fact, this project took part of the implementation of the LSS principles to obtain its MBB certification. The case study was intended to document the actions identified in the firm's management review. The research used primary as well as secondary sources. Observations were made during project meetings. Secondary sources consisted of project reports, meeting minutes, scorecards and multiple sources of evidence, such as $8 \mathrm{D}$ reports, supplier complaints, and corrective action reports (CAR), supplier non-disclosure agreements (NDA), confidential disclosure agreements (CDA), supplier self-disclosures, supplier selection assessments, quality assurance agreements (QAA), supplier audit reports, delivery contracts, final reports and project plans (Yin, 2018). In addition, the case study is useful to refine the framework and illustrate how to use it in business practice.

Representative collocations in complaint management were verified through reliable dictionaries, like Leo (2020), Redensarten-Index (2020) and Lexico (2020), the database Deutsches Referenzkorpus (DeReKo, 2020), and the consultation of informants Leo (2020). The analysis draws on Gross (1975)'s lexicon-grammar theory and object class theory (Gross, 1995), as well as on a study by Mogorrón Huerta (2014). Gross (1995)'s object class theory offers an extremely useful methodology for compiling electronic dictionaries - and, since this paper is intended as a contribution to the phraseological database that is currently under development at the University of Alicante, this methodology is ideally suited to that purpose.

The database currently consists of over 100 English-German expressions that have been compiled in two distinct phases. In the first phase expressions were collected from German documents, especially complaint management process documentation; in the second phase, from English documents related to the supplier complaint process and Lean Six Sigma. An object class called NomComplaint, related to supplier complaint management process, was defined according to Gross (1995). An example of this classification is: "complain to the supplier/G:nm/T:Concrete/C: $<$ NomComplaintt $>/$ Ger: bei dem Lieferanten reklamieren". Phraseological units were additionally classified based on syntactic and semantic features, as proposed by Gross (1975), with six categories available: "Human", “Animal”, 'Vegetable', "Concrete", "Locative" and "Abstract") (Gross, 1975). A phraseological unit can fall into one or several categories. The NomComplaint class is of particular interest because it provides an intersection between specialist and general language. This research work is based on the concept of object classes, developed by Gross (1995), and the lexicon-grammar theory of Gross (1975). Phraseological units used in complaint management process are mostly related to 3D-, 5D-, 8D-reports and internal or external complaint management activities, and are therefore classified as "Concrete" according to their syntactic and semantic features.

\subsection{Phase 1 of the DMAIC process - Define}

\subsubsection{Six Sigma Project}

Improvement of supplier performance data by reducing supplier related costs, standardizing processes and enacting continuous improvement with focus on the supplier complaint process and its effectiveness. 


\subsubsection{Problem Statement}

Lower than expected supplier performance, also described as late deliveries and a high supplier quality defects rate per purchase order. These results in chargeability variances have a high negative impact on service margins.

\subsubsection{Goal Statement: Expected Results - Business Case}

Improvement of supplier delivery and quality figures in 100 complaints, while maintaining planned fee adjustment. Hard benefits of over $€ 30,000$ could be obtained by reducing supplier complaints. Inspection costs and additional testing costs on finding defects are estimated to be an extra $€ 80$ per complaint. In the supplier qualification process, selecting the right supplier saves $€ 10,000$ per supplier. Cases of wrongly selected suppliers originate extra costs to the firm estimated at over $€ 40,000$. These costs can be saved by selecting and evaluating the firm's suppliers through a methodical and structured supplier management process. Corrective action plans are prepared and implemented at the beginning of 2016 . Benefits are evaluated for 12 months after the implementation.

Soft benefits are also in the focus of the case study. Customer satisfaction can be improved by reducing quality defects, including saving complaints handling time and reducing delivery delays. A team is set up and a champion is appointed. The project plan with the related milestones per category is defined. COPQ is calculated from the information summarized in the supplier complaints recorded in the firm's SAP database. Thus, the COPQ from the firm's production line due to late delivery and defected parts supplied is high. These costs would disappear if there were no deficiencies. As part of the Define phase of the DMAIC framework, an SIPOC (Suppliers, Inputs, Processes, Outputs, and Customers) methodology is chosen to provide an overview and help in defining a new process. SIPOC is a process improvement quality methodology that summarizes the inputs and outputs of one or more processes and is widely employed in Six Sigma projects, emphasizing the voice of customers and filled from the customer upstream to the supplier. In the designed SIPOC, 5 subprocesses are defined, namely: (1) selecting right supplier; (2) placing orders with all required information; (3) sending orders confirmation; (4) delivering parts from the purchase order; and (5) performing the incoming quality inspection. The SIPOC is a very useful tool to map the process level. Additionally, after a brainstorming session, a detailed process map is drawn up. The process map illustrates the relevance of delivering failure-free parts at the firm's incoming area on time. Otherwise, delivered parts are returned to the supplier and a supplier complaint must be recorded in the SAP database.

\subsection{Phase 2 of the DMAIC process - Measure}

As part of the Measure phase relevant questions are formulated, especially:

- How many suppliers are neither selected nor evaluated correctly?

- What are the total COPQ related to supplier incidents like non-delivery and logistic delays, shortages or failure-related costs?

- How many production and customer complaints are originated by supplier-related failures?

- What are the total costs of supplier complaints and how it is defined and measured?

- Does the firm have created emergency plans for single sources?

- Is the supplier failure rate periodically monitored?

A data collection plan was developed about information sources, possible KPIs (Key Performance Indicators) and those who can provide that information at the firm. The data collection plan is performed and summarizes the implemented KPIs, their definition, the 
department in charge to perform the evaluation, the method and tool used for that purpose and the intervals defined for performing the evaluation. Thus, the main defined KPIs are (1) the number of suppliers not qualified correctly; (2) revenue shortfall due to not deliver ontime, call-back actions and production stops; (3) the number of supplier complaints; (4) the back charge cost; (5) failure classification of supplier complaints; (6) the number of corrective actions and deviations identified during the initial sampling process. All the data is obtained from the ERP system. Thus, any person can perform an evaluation automatically, by selecting the related configured layout from the ERP system and having access to the related transaction. The evaluation is mainly performed by the quality department during the quality circle meetings which are set monthly.

\subsubsection{Validating the measurement system}

- Testing supplier KPIs in terms of on-time deliveries and number and impact of quality defects.

- Evaluating supplier assessment sheets and number of repeated qualified supplier complaints.

- Comparing suppliers belonging to the same material group for repeatability failures and for accuracy.

\subsubsection{Measuring baseline performance}

Performance is measured by evaluating the extent to which the target of the project has been reached, as described below:

The main goal is to reduce the number of complaints in and the related SCOPQ for the first implementation year in at least 10\%. Collateral benefits like improving the processing time of the complaints and reducing failures and time of employees are expected too. A Pareto diagram of the suppliers with the most number of complaints in the year 2015 is displayed in Figure 1. The Pareto diagram shows that supplier A accounts for a considerable proportion of the total COPQ. Therefore, this study investigates the main failures and root causes related to that supplier. Supplier A is a manufacturer of electrification products, especially low voltage circuit breakers. The top issues and critical failures for supplier A are investigated and summarized in the study.

Top critical failures and root causes from the supplier A (Firm A in the Figure 1) are analyzed and categorized into: (1) Latching failure of electronic devices in combination with additional devices; (2) or without combination; (3) Device works out of tolerance; (4) Device doesn't trip; (5) Test button from the device clamped; (6) Continuity malfunction of the device; and (7) Device dimensions out of the tolerance. The highlighted common root causes are: (1) wrong setup of the device; (2) Incorrect adjustment of molding tool; (3) Length of mounted parts out of specification; (4) Welding electrode got worn; (5) Assembly failure; (6) Incorrect tampoprint; and (7) Connection axle bent. 


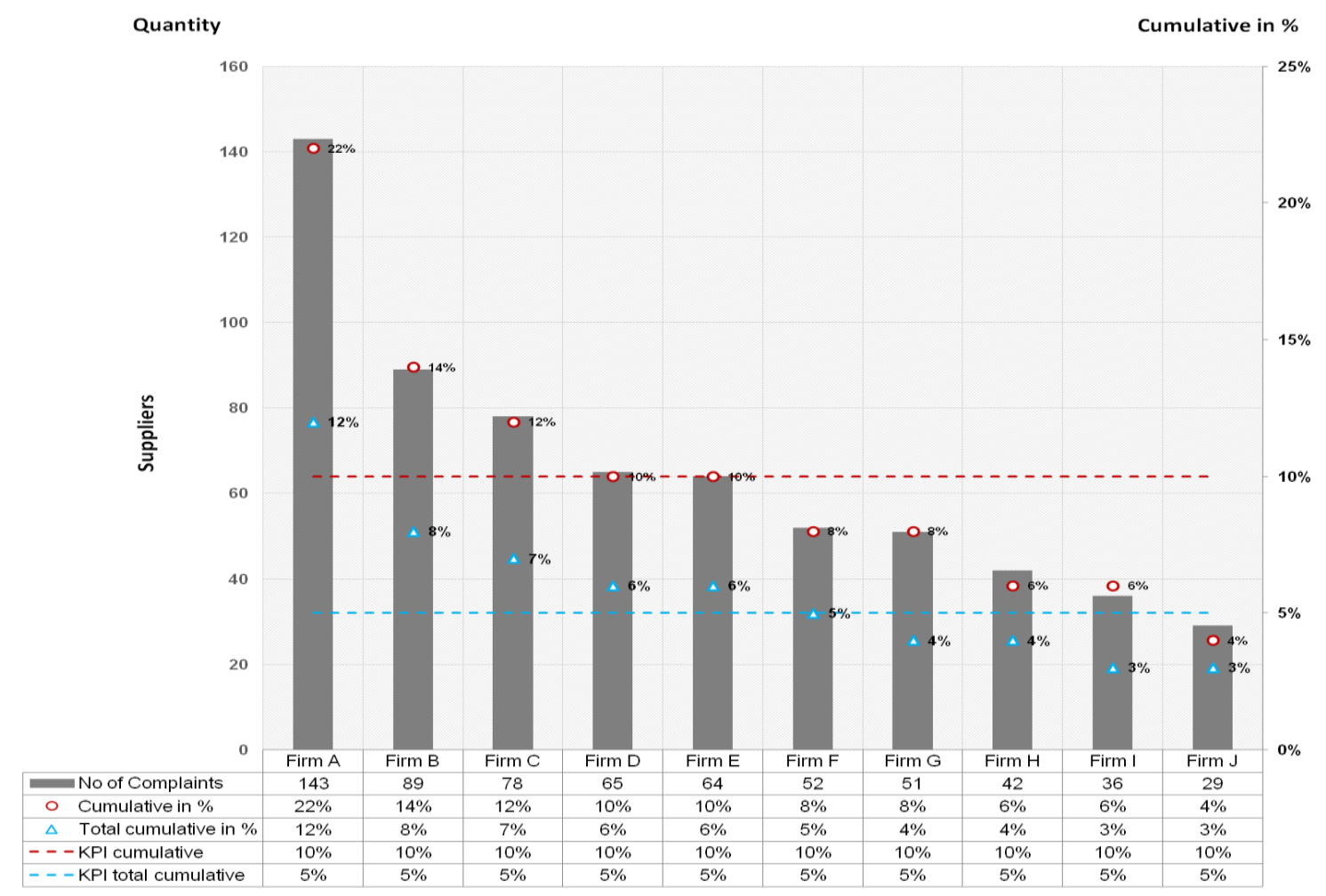

Figure 1. Pareto diagram - Top 10 suppliers by number of complaints

\subsection{Phase 3 of the DMAIC process - Analyze}

Hypotheses are tested during the analyzing phase:

$Y_{1}$ : Supplier management process is outdated and unclear.

$\mathrm{Y}_{2}$ : Employees are not trained periodically.

$\mathrm{Y}_{3}$ : Implemented failure delivery rate definition deviates from firm's defined scorecard values.

$\mathrm{Y}_{4}$ : Complaint failure description is missing or not completed.

$\mathrm{Y}_{5}$ : Complaint extra costs process is missing.

$\mathrm{Y}_{6}$ : Supplier selection process is outdated.

$Y_{7}$ : Repeated and recurrence failures are not specially monitored.

$\mathrm{Y}_{8}$ : The procurement process is outdated.

$\mathrm{Y}_{9}$ : Defects caused by lack of training and awareness.

\subsubsection{Cause-and-effect diagram on vital few categories}

As part of the analysis phase, an Ishikawa diagram (also called fishbone diagram) is employed. Ishikawa (1968) created in 1968 this cause-and-effect diagram. The "high supplier-related costs" are caused because the inefficiency of the supplier complaint process and the lack of regular training of employees. Further potential factors causing the overall high supplier-related COPQ are identified. Each cause for imperfection is a source of variation, which is usually categorized into major clusters to identify and classify the variation sources. The process is not standardized which does not comply with LSS principles.

\subsubsection{Summary results of hypotheses tested}

$\mathrm{Y}_{1}$ : Supplier management process needs to be updated and standardize - TRUE

$\mathrm{Y}_{2}$ : Employees need to be trained regularly - TRUE

$\mathrm{Y}_{3}$ : Failure delivery rate definition needs to be standardize- TRUE 
$\mathrm{Y}_{4}$ : Failure description needs to be standardize according to the 8D-methodology- TRUE $\mathrm{Y}_{5}$ : A process for charging complaints related costs to suppliers need to be updated-TRUE $\mathrm{Y}_{6}$ : A process for the supplier selection needs to be updated-TRUE

$\mathrm{Y}_{7}$ : The effectiveness of the implemented corrective actions needs to be verified in the mass production deliveries - TRUE

$Y_{8}$ : The procurement process needs to be updated - TRUE

$\mathrm{Y}_{9}$ : A training plan must be created - TRUE

Finally, an FMEA (Failure Mode and Effects Analysis) tool is used in the analysis phase to determine which actions have more influence on COPQ. The supplier quality complaint process is the most influential action, with the major Risk Priority Number [RPN] of 512. RPN is used when assessing risk to help identify critical failure modes associated with the process. The FMEA tool is widely used in the electronics industry for the evaluation of related risks and potential failure effects according to their RPN, which is calculated for each failure mode by multiplying severity (the effect of a failure), occurrence (likelihood of occurrence) and detection (effectiveness of the controls to prevent or detect the cause). Tested theories are listed in the "Process step" column of the FMEA.

\subsection{Phase 4 of the DMAIC process - Improve}

Solutions for proven $X_{s}$

- Updating the supplier complaint process in firm's management system $\rightarrow \mathrm{Y}_{1}, \mathrm{Y}_{2}, \mathrm{Y}_{4}, \mathrm{Y}_{5}$, $\mathrm{Y}_{6}, \mathrm{Y}_{8}$

- Planning an in-house training for all employees involved $\rightarrow \mathrm{Y}_{2}, \mathrm{Y}_{4}, \mathrm{Y}_{8}, \mathrm{Y}_{9}$

- Updating the firm's definition of KPIs and standardizing them throughout the process $\rightarrow$ $\mathrm{Y}_{3}, \mathrm{Y}_{9}$

- Updating compensation agreements with suppliers related to refund caused supplier complaints costs $\rightarrow \mathrm{Y}_{1}, \mathrm{Y}_{2}, \mathrm{Y}_{5}$

- Investigating root cause of repeated failures and verify the implemented corrective actions in the future mass production deliveries $\rightarrow \mathrm{Y}_{4}, \mathrm{Y}_{7}, \mathrm{Y}_{9}$

- Re-evaluating critical suppliers and creating a second source plan $\rightarrow \mathrm{Y}_{1}, \mathrm{Y}_{2}, \mathrm{Y}_{5}, \mathrm{Y}_{7}$

The analysis confirms that the supplier complaint process is the key to improving supplier performance and saving supplier-related COPQ. Therefore, the process is created, released and published through the firm's management system (ViFlow) as shown in Figure 2. The supplier complaint process is part of Medina-Serrano's dissertation (2019) and it's attached in the Annex 2, Figure 5. The complaint handling process for purchased materials and services is based on the $8 \mathrm{D}$ methodology of problem solving to approach and to resolve problems, namely: (D1) Team: Who is going to be part of the problem-solving team and who will lead it? What skills and roles are needed? Establish a multidisciplinary team for to support an specific complaint process; (D2) Describe the Problem: Summarize the problem. Give details on when and how often it occurs? Describe how the problem manifests including any data to document the problem. Is there any history that is relevant to the problem? Specify the problem using the is/is not methodology answering also who, what, where, when, why and how many related to the problem. The problem is as precise as possible to define whereby the core of the problem should be worked out and quantified. The problem description is the starting point of the $8 \mathrm{D}$ analysis. All work takes place in a system in the processes interwoven into each other whereby deviations can occur; (D3): Create containment action plans: Are there any mitigating steps that can be taken while problem-solving is taking place? What temporary measures can prevent the problem from worsening until a permanent solution is identified? Define and implement containment actions to minimize the impact of 
the problem. Immediate measures help to limit the damage and should prevent the further spreading of the problem until a permanent solution is found. In this phase, the objective is to protect the customer from further damage. Immediate measures in the $8 \mathrm{D}$ report can be: replacement deliveries, sorting of questionable materials, interrupt the particular production, goods returned for repair, routine tests, etc. Error management means, to take responsibility. If defective parts are in circulation, they can not only affect the function of the products but also affect the customers; (D4) Determine and identify root causes. Why an error occurred? Why was the error not detected? And Why was the error not prevented? List all possible causes which could explain why the problem occurred. Root cause analysis techniques such as Five whys and Ishikawa diagrams can be used to map possible causes against the problem identified; (D5): Verify and develop Permanent Corrections for Problem that will resolve the problem. What permanent solution or solutions could be implemented? Is there a deadline? How will you know if it is effective? Measurements that can eliminate the root causes are determined. The optimal measure(s) are selected and proved through tests that the problem can be effectively and efficiently solved and there are no undesirable side effects. When establishing the measurements the error prevention and not the error detection is in the forefront. Using pre-production programs, quantitatively confirm that the selected correction will resolve the problem. (Verify that the correction will actually solve the problem); (D6) Define and Implement Corrective Actions. Who is responsible? When is the deadline? The corrective actions can have an impact on the process parameters, product specifications and other specification documents as well as test methods and the staff qualification. After the successful implemented permanent corrective actions, the containment actions are cancelled. In the automobile industry, it is specified that only process-improving measures are allowed as corrective measures in line with the 8D-process. Personnel measures such as exhortations, courses or trainings are not considered as process improving. Also, validate corrective actions with empirical evidence of improvement; (D7) Prevent Recurrence / Systematic failures. What measures can be implemented to prevent a similar problem? Are there any lessons that can be applied elsewhere? Preventive actions must ensure that same or similar errors are eliminated in the future. The effectiveness of the adopted measures is - e.g. by increasing the inspection severity - monitored over a reasonable period. The corrections must be included permanently in the organisation e.g. working instruction, Inspection plan, drawing, working plan, etc. Document any learning that came from this process. Modify the management systems, operation systems, practices, and procedures to prevent recurrence of this and similar problems; (D8) Congratulate the main contributors to the team. Express appreciation. What reward would be meaningful to the team? How could this help with future problem solving? The joint effort is appreciated and the experiences exchanged. Also, here is the space for the closing remarks e.g. complaint acknowledged or complaint rejected. The team needs to be formally thanked by the firm.

The developed process is described as follows: (1) evaluate the non-conformity. There are three main origins identified for the complaint process which are (1) non conforming materials identified from the incoming quality inspection; (2) from the production; or from the customer. The quality assurance (QA) employee coordinate the process and edit the notification, entering the required information such as roles, purchase order information, status, create error description for notification of defects, determine actions to be taken together with the team, adding internal expenses. (2) Code? Coding is used to structure different process flows for non-conforming results (defective products) with supplier reference in supplier notifications. Five different codes are defined:-S001 for complaint at supplier; -S002 for Testing exception / Inspection exception;-S003 for Rework in house; S004 for Technical clarification/revision; and -S005 for blocked materials, parts. 
Notifications with code S001 "complaints at suppliers" in relation to purchase order items are used for vendor evaluation. (3) Create complaint.

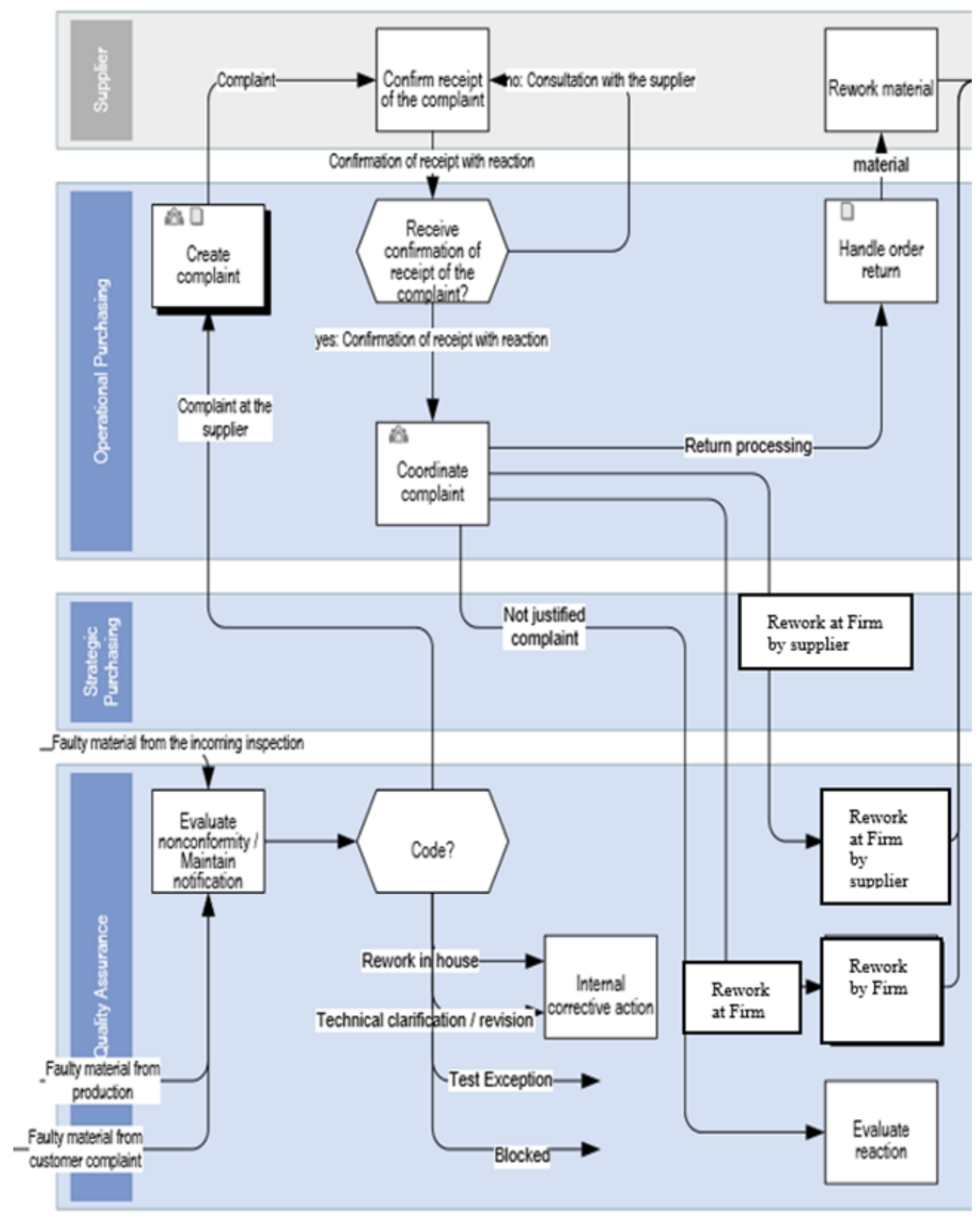

Figure 2. Supplier complaint process flow (Medina-Serrano, 2019)

QA coordinates in consultation with the operative purchasing. The priority of the complaint is set appropriately with regards to its impact. A reworking sub-process is created within the supplier complaint process, also defining all the steps to follow and the required documentation. The prioritization of supplier complaints is defined in a sub-process and includes several priority levels. Priority 1: safety relevant failures; failures from customer 
complaints; failures which can lead to shortages, production stops, customer recalls, human damages, extremely long delivery delays and internal costs with a COPQ estimated at over $€ 1,000$. For these cases, the firm has defined the following expected reaction plans and actions for suppliers. Expected reaction: Internal: operative purchasing complaint to the supplier within 24 hours on working days:

External: supplier - Presence of a qualified representative of the supplier on-customer site Determination of extent of damage, limitation of damage - Initiation of failure analyses for the affected products - Provision of error-free products (replacement delivery) - 8D report must be generated within 10 working days, (if applicable: after receipt of returned goods), (8D-template can be edited with Adobe Reader comment functions by supplier) Priority 2: Repeated failures and failure costs (total costs of e.g. production stop, delivery delay, internal expenses $100 €-1000 €)$. Priority 2 complaints are intended for complaints which are non safety relevant. Internal reaction: operative purchasing complaints to the supplier within 72 hours on working days. External reaction: Supplier sends a confirmation of the received complaint within 24 hours. - Determination of scope of error, damage limitation - Initiation of failure analyses for the affected products - Provision of faultless products (replacement delivery) - 5D report must be generated within 10 working days.

Priority 3: Low relevance minor impairment, corrective actions must be implemented by the supplier before the next delivery. Failure costs (total costs of e.g. production costs, delivery delay, internal expenses) between $0 €-100 €$. Internal reaction: Operational purchasing Complaint to the supplier within 5 working days External reaction: Supplier Confirmation of receipt of the complaint within 2 working days No statement required. Typical priority 3 complaints are parts delivered with damaged packaging, etc. Complaints are sent to supplier through the operative purchasing department, prior describing the expected reaction of the supplier and the required documents such as 8D-Report, 5D-Report, credit notes, etc. specifying a deadline for the reports. For the internal monitoring of the supplier reaction, a task is raised in the system with a deadline to set alerts to the responsible operative purchaser to follow-up supplier reaction. A template with the 8 disciplines methodology of the 8Dreport is provided to the supplier with reference to the raised notification number, the failure description, pictures, and reference to the original purchase order, contact person and further information. If the failure is caused by the supplier, then depending on the appropriateness a statement or an $8 \mathrm{D}$ report with the complaint is to be requested. The response is monitored by the responsible employee of the purchasing department.

A corrections task is created in the notification. (4) Supplier sends a confirmation of the received complaint. (5) Is there a confirmation of the complaint received from the supplier? A confirmation is expected within 24 hours. If there is no confirmation of the complaint, the operative purchasing department will contact the supplier. Is there a statement including containment action plans for the complaint received? If there is no such information, the operative purchasing department will request them to the supplier. (6) Coordinate the complaint. If the complaint is not qualified because for example the parts or materials are out of the warranty period, the reaction will be internally evaluated. Otherwise, the parts or material can be reworked at the firm by the supplier or by the firm is allowed to rework the parts by its own, or the material will be returned to the supplier.

Rework at Firm by supplier: coordinate rework, perform rework, enter costs for reworking the notification. Rework at Firm: coordinate rework, perform rework, enter costs for reworking the notification and charge the rework costs to the supplier prior agreement.

(7) Processing returns orders. The defected parts are returned via (in agreement with) the responsible operative purchaser. In principle, the return of the goods with return order is carried out. Replacement deliveries are automated placing new orders. Supplier send a confirmation of the receipt defected returned parts. Coordinate complaint and further 
procedure together with the supplier. (8) Perform analysis and implement measures. For priority 1: Within: 2 working days after receiving the defected parts (first results); 5 working days - obvious root cause and implement containment actions; 10 working days (8D report). For priority 2 complaints an $8 \mathrm{D}$-report is expected within 10 working days. (9) Is the feedback received from the supplier in the indicated reaction times? If no feedback is received, the operative purchaser will send a reminder / warning to the supplier. If after sending a reminder, the supplier does not react, the complaint will be escalate to the strategic purchaser. If a feedback is received, the response will be internally evaluated. (10) Is the effectiveness of the implemented measures proven? If not, a follow-up action plan will be initiated with the supplier. Once, the effectiveness is proven, (11) a final credit note with the replacement of defected goods will be requested to the supplier. (12) Documentation of all related information related to the complaint such as internal and external correspondence, analysis reports, 8D-reports, etc. (13) Once the notification is updated and all information is documented, an inspection plan for the next deliveries of the supplier will be especially set at the incoming quality inspection to prove the effectiveness of the implemented corrective actions. After all actions are completed, the notification can be closed (14) and communicated to the people involved. Lessons learned will be accordingly documented. As part of the process, automated tasks has been later on programmed at the ERP system (Figure 4.1 and Figure 4.2). Thus, people working in the process can standardize jobs, saving time and avoiding failures. Poke yoke effect is also an efficient methodology to help employees to avoid failures. Some of the automated tasks are attached in the Annex 2. Standardized complaint letters in English and German are created and enclosed in every complaint (Annex 1). A standardized complaint letter is shown in Table 2.

Table 2.

Standardized complaint letter in English

Dear Sir or Madam,

Please find attached our complaint, recorded under the above referred complaint number. This is required for future correspondences.

We point out that the related Operative Purchaser is the main contact person. However, we have sent the complaint direct to you in order to speed up the complaint process.

Please follow our expected timeline for the complaint processing time.

\section{Timeline:}

The regular process time for the entire supplier complaint-handling procedure is 10 working days. Based on this timeline of the complete process, the following rules apply for external providers.

- Clarification of open questions and first statement within $\mathbf{2 4 h}$.

$>$ Acknowledge receipt of complaints

$>$ Evaluation of expected loss

$>$ Prepare failure free replacement deliveries

$>$ Conduct failure analysis for defected products

- The 8D-Report within 10 working days.

- If the 8D-Report cannot be finished within 10 working days, a status Report (4D-Report) has to be sent.

\section{Handling of defective samples:}

- The affected parts are returned via the responsible operative purchaser.

If you have any questions, please do not hesitate to contact us. 


\subsection{Phase 5 of the DMAIC process - Control}

After the project is implemented, the process is created and the employees are trained according to the new process and the updated documentation. The number of complaints is reducing in over 200 complaints in the first year of implementation of the new process which counts for a reduction of over $20 \%$ of the complaints to the previous year. The supplier failure rate decreased and the COPQ improved significantly. In fact, after the implementation of the project, the DPMO value, calculated from data from the firm's SAP database and the equation below, greatly improved. DPMO $=$ (Number of defects *1,000,000) / ((Number of defect opportunities / Unit) * Number of Units). A Pareto diagram of the suppliers with the most number of complaints in the year 2016 is displayed in Figure 3.

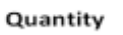

Cumulative in \%

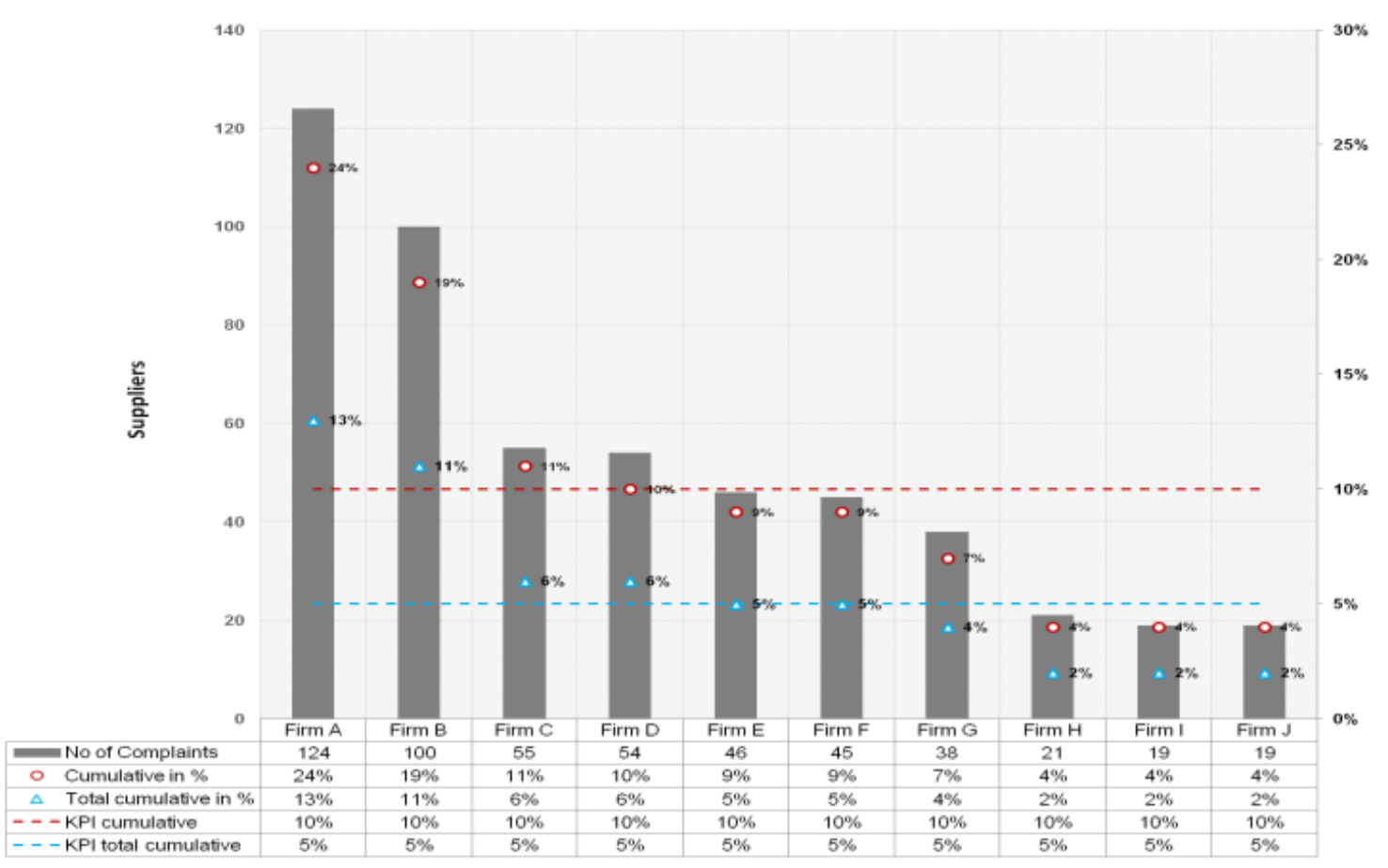

Figure 3. Pareto diagram - Top 10 suppliers by number of complaints

\section{Discussion and Conclusion}

Managing complaints is essential for transparency and to make sure that vendor and client are operating in the right way. Documenting the procurement process is essential and can provide the reasoning for how a decision was made. Vendor will review the issue, look over the documentation, discuss it internally and with the supplier and definitely make and communicate a decision. Complaints are a valuable source of feedback and an important tool for business and staff development. Therefore, it's key to develop a history of issues against each supplier to assess performance. Diligent and prompt attention to complaints can help firms identify the needs of their customers and stakeholders, understand their business shortcomings, increase customer satisfaction and improve overall performance. Besides the description of the failure, suppliers would require detailed information about the complaint, such as ID-number, model, evidence of the complaint like pictures, lab report, etc. The complaint should be shared with the supplier as soon as possible to speed up the complaint process. The supplier should receive the contact data of a person who can be contacted for further information. The research presented in this paper has significant theoretical and practical implications in supply chain management in general and logistics and outsourcing management in particular. It has often been claimed in recent years that further studies were needed on the operationalization of the Six Sigma methodology to improve the COPQ related 
to external providers. This research identifies the need to regularly monitor the performance of complaints to the management review team. The report should highlight the performance of the complaints management system over the previous twelve months and should include (but is not limited to): (1) number and nature of complaints recorded during the reporting period; (2) number of priority 1 complaints; (3) processing time of complaints; (4) total of credit notes received compared with the total of credit notes requested; and (5) total of internal costs recorded at the system. This paper advances a framework for reducing supplierrelated COPQ by improving and standardizing the supplier complaint process in a firm, including multilingual templates for the employees involved. Besides of the main goal of investigating Six Sigma's role in reducing quality costs, research results demonstrate the advantage of standardized multilingual texts for the complaint process of global players. The project validates the effectiveness and efficiency of the DMAIC methodology as a framework that has been demonstrated to help organizations identify various initiatives for optimal reduction of quality costs. Even though Six Sigma is more widely accepted in many organizations nowadays, in-depth case studies on this methodology are still scarce. The firm analyzed decided to reduce quality costs and improve supplier-related processes using Six Sigma methodologies to achieve manufacturing excellence, which is essential if one is to survive in the global competitive market. The Just in Time (JIT) principles from the lean methodology were applied by Nimeh, Abdallah and Sweis (2018), however, they can not be always implemented. For instance, at pandemic times like the years 2020-2021 were COVID19 led to travel restrictions and allocations at the supply chain. As Medina Serrano et al. (2020) pointed out, this COVID-19 pandemic crisis will pass, but it has served to demonstrate the dependence of the firms on their suppliers and the global dependency of firms with their supply chains (Mediana-Serrano, et al, 2020).

The percentage frequency of occurrence of the expressions analyzed of the selected corpus can be observed. There were 3,410,000 results for the collocation "to complain about something" on www.google.com on 12/02/2021, 35,500 for "etwas bemängeln" (German equivalent) and 5,690 for "trouver à redire à quelque chose" (French equivalent). In fact, "trouver à redire" obtained 178,000 results. The results of the paper highlight the relevance of building cross-functional teams for achieving continuous improvement (Nimeh, Abdallah and Sweis, 2018) and implementing suitable and proven tools as needed. This study, for instance, implements FMEA, SIPOC and process mapping tools, among others. Practitioners and researchers want to know which methodology best fit for a certain process improvement. In fact, KVP (Kaizen), Lean (PDCA) and Six Sigma (DMAIC/DMADV) methodologies can be applied for the improvement of processes. One of the main selection criteria relies on the scope's grade. Whereas KVP is preferred for small scopes with a low grade of difficulty, Lean is applied primarily for scopes as part of processes with few interfaces and medium grade of difficulty. Finally, Six Sigma is the most suitable methodology for scopes with a high grade of difficulty or problems involving cross-functional processes. Therefore, the applied Six Sigma methodology suited with the initial problem statement.

SCOPQ is defined as the costs associated with defects and deficiencies originated by suppliers. For instance, they could include the costs for: supplier-related incidents like nondelivery and logistic delays, shortages or failure-related costs, monitoring costs, production stop costs, rework costs, complaints, administrative costs, etc. This research not only validates the proposed framework through an in-firm case study, but also confirms the relevance of mitigating and avoiding biases and recommends standardizing processes and regularly training the employees involved. Unlike Gaikwad et al. (2016), this study uses an FMEA tool to evaluate risks and prioritize an action plan in order to obtain greater benefits during the analysis phase. In fact, one of the aims of this research is to reduce COPQ by standardizing the supplier complaint process and training the employees involved. Thus, Six 
Sigma strategies seek to improve output quality in a process by identifying and removing the causes of defects and minimizing variability in manufacturing and business processes, thus obtaining long-term improvements across the organization. Using a digital complaints management system can have several advantages for the suppliers as for the buying firms. In contrast to Murumkar et al. (2018) framework for quality cost reduction, this study aims to reduce defects, with a focus on COPQ and the impact of supplier related quality costs verifying its efficiency through a case study in Germany. This research study adopts Bustos's (2020) definition of collocation and focuses on expressions used in complaint management. It should be pointed out, however, that the term "collocation", as defined by Bustos, refers to different concepts in English, French and German languages. This research follows Gross's (1975) lexicon-grammar theory and object class theory (Gross, 1995) focusing on only one class, complaint management activities. Research results can be a valid guide for training purposes and especially for translations and reporting of 8D-reports. The influence of anglicisms in the complaint management process in the industry has been observed in this research work. Research results demonstrate the influence of English collocations as the majority of the specialized literature is written in English and English is the preferred and most used vehicular language for business purposes.

Notwithstanding the above findings and contributions, this study faces a number of limitations and so do its outcomes. Firstly, a potential limitation of this study stems from the fact that the in-depth analysis focuses exclusively on one case study, without comparing it to other case studies. Secondly, the proposed framework was applied in the electronics industry in Germany; therefore, its application to different sectors, branches and regions can be addressed. Additionally, this research focuses on phraseological units employed in complaint management activities and therefore the results are valid exclusively for this field. However, the findings from this study seem to provide a valuable understanding of the current situation in this research field. The present paper equally suggests several future research strands, which may encourage more intensive studies in this important area. Researchers can develop the proposed framework by integrating additional criteria for evaluating and prioritizing scenarios to reduce supplier-related COPQ and enhance the efficiency of the approach.

\section{References}

American Society for Quality (ASQ), (2019). What is Six Sigma? Available: https://asq.org/quality-resources/six-sigma, access on: 05.03.2019.

Belhadi, A., Kamble,S.S., Zkik, K., Cherrafi, A. And Touriki, F. E. (2020). The integrated effect of Big Data Analytics, Lean Six Sigma and Green Manufacturing on the environmental performance of manufacturing companies: The case of North Africa, Journal of Cleaner Production, Vol. 252, https://doi.org/10.1016/j.jclepro.2019.119903.

Bustos, A. (2020). ¿Qué son las colocaciones? Blog de Lengua Española: el libro Madrid/Cáceres, ISSN 2529-8461, https://blog.lengua-e.com/2010/que-son-lascolocaciones/. Last accessed on 24/10/2020.

Conger, S. (2015). Six Sigma and Business Process Management. In: Brocke J., Rosemann M. (eds) Handbook on Business Process Management 1, International Handbooks on Information Systems, Springer, Berlin, Heidelberg.

Deutsches Referenzkorpus (DEREKo) (2020). Deutsches Referenzkorpus, https://korap.idsmannheim.de/. Last accessed on 15/01/2021.

Gaikwad, L. M., Teli, S. N., Majali, V. S. and Bhushi, U. M. (2016). An Application of Six Sigma to Reduce Supplier Quality Cost, Journal of the Institution of Engineers (India): Series C, Vol. 97, No.1, pp. 93-107. 
Gerger, A. and Firuzan, A. R. (2016). Use of Six Sigma Method as a Process Improvement Technique: a case study in aerospace industry, Academic Journal of Science, Vol. 6, No.1, pp. 191-202.

Gross, G. (1995). À quoi ser la notion de partie de discours? Les classes de mots, Traditions et perspectives, Presses Universitaires de Lyon, 217-231.

Gross, M. (1975). Méthodes en syntaxe: régime des constructions complétives, Hermann, ISBN $270561365 X, 9782705613655$.

Herbst, R. and Ammann, R. (2000): Dictionary of Commercial, Financial and legal terms, OTT Verlag, Fifth Edition.

Ishikawa, Kaoru (1968). Guide to Quality Control. Tokyo: JUSE.

ISO 18404 (2015). Quantitative methods in process improvement -- Six Sigma -Competencies for key personnel and their organizations in relation to Six Sigma and Lean implementation, Available: https://www.iso.org/standard/ 62405.html, access on: 05.03.2019.

Laureani, Alessandro and Antony, Jiju (2017) Leadership and Lean Six Sigma: a systematic literature review, Total Quality Management and Business Excellence, pp. 1-29, ISSN 1478-3363.

Leo (2020): Leo. Consulted on 09.05.2020, <https://www.leo.org/>.

Lexico (2020): Lexico. Consulted on 24.05.2020, <https://www.lexico.com/>.

Machowski, F. and Dale, B. G. (1998). Quality costing: An examination of knowledge, attitudes, and perceptions, Quality Management Journal, Vol. 5, No. 3.

Mahender Singh K. and Rajeev R. (2020). Green Lean Six Sigma for sustainable development: Integration and framework, Environmental Impact Assessment Review, Vol. 83, https://doi.org/10.1016/j.eiar.2020.106396.

Medina-Serrano, R. (2019). Strategic Sourcing Management - A Multiple Criteria Decision Support Methodology with TOPSIS, Ph.D. Dissertation, Alicante University.

Medina-Serrano, R. (2020). A contrastive analysis of traceability expressions: a corpus-based study of German-English collocations, Congreso Internacional Nodos del Conocimiento 2020, Universidad, innovación e investigación ante el horizonte 2030, Dykinson S.L., ISBN "978-84-1377-325-4.

Medina-Serrano, R., Gonzalez, R., Gasco, J.L. and Wellbrock,W. (2020). Coronavirus (COVID-19): How to Secure the Supply Chain?-A Case Study, International Journal of Supply Chain Management, Vol. 9, No. 6, 8 pages.

Mellado Blanco, C. (2015). Parámetros específicos de equivalencia en las unidades fraseológicas, Revista de Filología, 33, 153-174, http://riull.ull.es/xmlui/handle/915/4591.

Mellado Blanco, C. (2019). Phrasem-Konstruktionen kontrastiv Deutsch-Spanisch: ein korpusbasiertes Beschreibungsmodell anhand ironischer Vergleiche, Yearbook of Phraseology, 10, 65-88. DOI: 10.1515/phras-2019-000.

Message Costa, L.B., Godinho Filho, M., Fredendall, L.D. and Devós Ganga, G.M. (2021). Lean six sigma in the food industry: Construct development and measurement validation, International Journal of Production Economics, Vol. 231, https://doi.org/10.1016/j.ijpe.2020.107843. 
Miles, M. B. and Huberman, A. M. (1994). Qualitative Data Analysis (2nd edition). Thousand Oaks, Sage Publications, CA.

Mogorrón Huerta, P. (2014): Importancia numérica de las variantes diatópicas españolas y su tratamiento en los diccionarios, De Gruyter, 5:123-144.

Murumkar, A. B, Teli, S. N. and Loni, R. R. (2018). Framework for Reduction of Quality Cost, International Journal for Research in Engineering Application and Management (IJREAM), DOI:10.18231/2454-9150.2018.0231.

Nimeh, H. A., Abdallah, A. B. and Sweis, R. J. (2018). Lean Supply Chain Management Practices and Performance: Empirical Evidence from Manufacturing Companies, International Journal of Supply Chain Management, Vol. 7, No. 1, pp. 1-15.

Redensarten-index (2020): Redensarten-index. Consulted on 9.05.2020, < https://www.redensarten-index.de/>.

Shivam G., Sachin M. and Angappa G. (2020) Big data in lean six sigma: a review and further research directions, International Journal of Production Research, 58:3, 947969, DOI: 10.1080/00207543.2019.1598599

Snee, R. D. (1999). Why should statisticians pay attention to Six Sigma? Quality Progress, Vol. 32, No.9, pp. 100-103.

Vaishnavi, V. and Suresh, M. (2020), "Modelling of readiness factors for the implementation of Lean Six Sigma in healthcare organizations", International Journal of Lean Six Sigma, Vol. 11 No. 4, pp. 597-633. https://doi.org/10.1108/IJLSS-12-2017-0146

Yin, R. (2018). Case study research and applications, Design and Methods (Sixth Edition), Sage Publications, London.

Zahar, M., El Barkany, A. and El Biyaali, A. (2015). Managing Cost of Quality in Laboratory of Water Analysis, Modern Applied Science, Vol. 9, No. 2, pp. 1913-1852. 


\section{Attachments}

Annex 1.

Standardized complaint letter (notification in German)

Sehr geehrte Damen und Herren,

im Anhang finden Sie unsere Mängelrüge, erfasst unter der oben genannten Meldungsnummer. Diese ist erforderlich für die zukünftige Korrespondenz.

Der zentrale Ansprechpartner ist der zuständige operative Einkäufer. Die Reklamationsmitteilung wird direkt zu Ihnen gesendet, um den Reklamationsprozess zu beschleunigen.

Bitte beachten Sie den zeitlichen Ablauf für die Bearbeitung der Mängelrüge, die wir in diesem Zuge erwarten.

\section{Zeitlicher Ablauf:}

Die reguläre Bearbeitungszeit für die gesamte Lieferantenreklamation beträgt 10 Arbeitstage. Basierend auf dieser Zeitvorgabe für den gesamten Reklamationsprozess, leiten sich für die Lieferanten folgende Regeln ab.

- Klärung aller offenen Fragen und Zwischenbericht innerhalb von 24 Stunden.

$>$ Zusenden einer Eingangsbestätigung

$>$ Schadensumfangsermittlung

$>$ Bereitstellen von fehlerfreien Ersatzlieferungen

$>$ Einleiten von Ausfallanalysen für die betroffenen Produkte

- Wir erwarten den 8D-Report innerhalb von 10 Arbeitstagen.

- Wenn der 8D-Report nicht innerhalb von 10 Arbeitstagen fertig gestellt werden kann, muss ein Statusbericht (4D-Report) verschickt werden.

Handhabung von Ausfallteile:

- Die Rücklieferung der betroffenen Teile erfolgt über den Operativen Einkauf.

Für Rückfragen stehen wir Ihnen gerne zur Verfügung.

\section{Annex 2. Supplier complaint process}

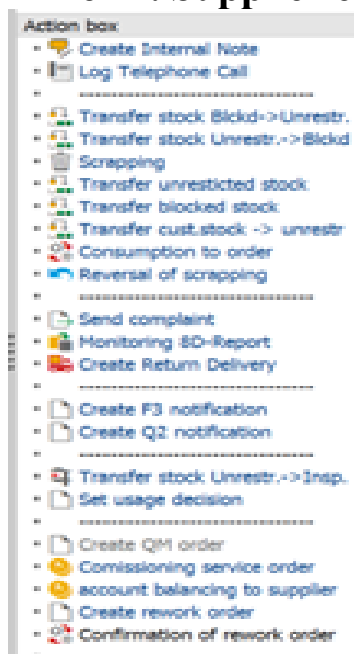

Figure 4.1. Automated actions from the action box

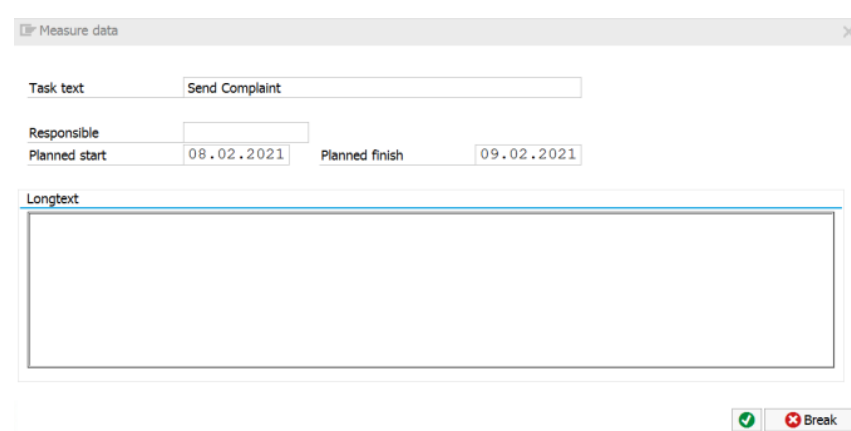

Figure 4.2. Automated task "send complaint" from the action box 


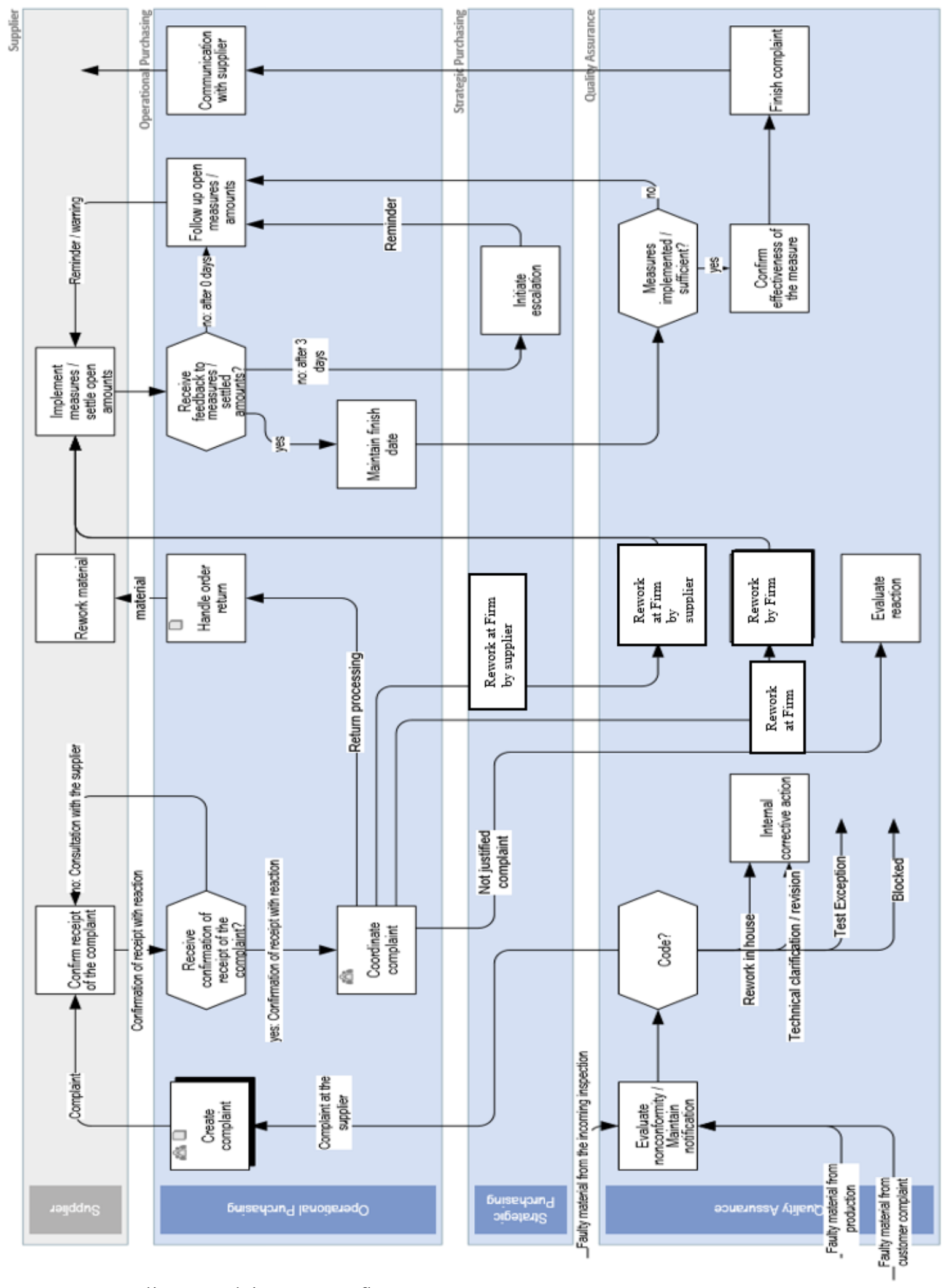

Figure 5. Supplier complaint process flow 